\title{
The Advertising Challenges of the Internet: the strategic perception of Florianópolis agencies
}

\author{
Mário Cesar Barreto Moraes ${ }^{1}$, Mariana Fraga Moreira ${ }^{2}$, Guilherme Felipe Kalnin ${ }^{3}$
}

Escola Superior de Administração e Gerência - ESAG/UDESC - mcbmstrategos@gmail.com

Escola Superior de Administração e Gerência - ESAG/UDESC - mari.fragamoreira@gmail.com

Escola Superior de Administração e Gerência - ESAG/UDESC - gfkalnin@gmail.com

KEY WORDS

Strategy;

Advertising;

Internet advertising;

Communication vehicles;

Publicity agencies

Received 04.07.2016

Revised 05.10.2016

Accepted 05.10.2016

ISSN 1980-4431

Double blind review

\author{
SUMMARY
}

This research aims to propose strategic actions in order to increase the development of the Internet communication vehicles in the context of Florianópolis from the perception of its advertising agencies, including the factors that influence media buying, the relationship between vehicle and agency and the challenges to be faced to the rise of the internet as advertising media.The research was divided into exploratory stage, in which befits documentary and bibliographic research, and descriptive stage, conducted through in-depth interviews with agency leaders. As a result, separate proposals were structured into four different perspectives regarding the relationship, training, regulation and results of agencies, and observe how major problem the difficulty of training, lack of knowledge of clients and low profitability coming from the internet in Featured advertising environment.

\section{Introduction}

Advertising face several challenges in recent decades, which, according Bringgs and Burke (2004) is marked by both the domain period of the mass media, where newspapers, radio and TV appear and predominate over the communication market, shifting part of the advertising budget business, as the rise of the internet, which turns the media consumption mode, opposing the mass media, now consolidated, decentralized and diverse. (Castells, 2002)

According to the Brazilian media research (BRAZIL, 2015), held across the country by IBOPE institute with a sample of 18,312 respondents of different characteristics, it appears that $48 \%$ of the largest Brazilian population 16 years has the habit of accessing the internet $55 \%$ has as usual the use of radio and $95 \%$ use the TV as the primary means of communication, however, also points out that socio-demographic characteristics, such as income and education, have high impact on the use of communication media to create social gaps depending on the technology. At the same time points as the main public internet user the young high family income.

When we look at the media investment on the Internet in 2014, according to Inter-Media Project (2015) a partnership between the Medium and Message group with Princewaterhouse Coopers consultancy operating since 1990 in the measurement of Brazilian advertising 
investmentsOnly $7.6 \%$ of advertising revenue cake are destined to the Internet, while $58.5 \%$ are for television, representing a total of $\mathrm{R} \$ 39.97$ billion recorded in the survey. Despite being considered the main source of information in relation to advertising investments, Inter-Media Project underestimates the internet layer to disregard important players such as Google and Facebook. Since the data submitted in 2014 by the Interactive Advertising Bureau (IAB Brazil), the main representative body of the Brazilian digital interactive segment about Brazilian advertising revenue on the internet, in partnership to comScore, finds the amount of $\mathrm{R} \$ 8.3$ billion. Thus, there has been a high distance between the two investments in Brazil. In the case of Santa Catarina, the revenue for the Internet are even lower because, according to Advertising Placement Market Research Santa Catarina (2013), conducted by the Institute Map, only $0.6 \%$ of revenue from advertising placement are sent to Internet.

The changes of technological paradigms, emerging from an era focused on the product for an era focused on the consumer, who now demadna flexibility and interaction is governed by changes in the market, reflected in increasing communication, as well as its segmentation and individuality ( OKADA, SOUZA, 2011). It is therefore necessary, according to Shimp (2009), a stream of change and constant updating by advertising agencies, requiring experimentation and adaptation of specialists, especially in the digital advertising market.

Advertising agencies play a decisive role in the choice of media used by their advertiser clients. Adler and Firestone (2002) report that the advertising market is sustained mainly in the relationship between: vehicle (producing content), public (consuming this content) and advertisers often represented by advertising agencies (who "buy" the associated hearing the vehicle). And secondO'Guinn, Allen and Semenik (2008) Media fragmentation is a major headache for advertising agencies, who are still struggling to figure out how to enter, and also the trademarks of their clients in this new environment.

Faced with the scenario presented, this study aims to propose strategic actions for the communication vehicles that use the internet, specifically in the city of Florianópolis, which examined the perception of advertising agencies, in order to understand the factors that influence media buying the particular contextAnd the relation between vehicle and agency and challenges faced by them due to the rise of the Internet as advertising media. In for it, it will first outline the theoretical framework on the subject.

\section{2theoretical framework}

It is intended to elucidate this topic on the seven themes that make up this research: Marketing; Communication, advertising and marketing; Internet advertising; Publicity agencies; communication vehicles; The relation between vehicle and agency; and Strategy.

\subsection{Marketing}

Organizations have always found in marketing a source of differentiation attributes to survive in the market. As a definition, the American Marketing Association (AMA, 2016), presents marketing as "[...] the activity, set of institutions and processes of creating, communicating, delivering and exchanging customer value offers, partners and society in general". Already Kotler and Keller (. 2012, p 3) defined as: "[...] activity, the body of knowledge and the processes of creating, communicating, delivering and exchanging offerings that have value for customers, clients, partners and society as a whole ", so that the definitions given to the term differ with social and managerial perspective, with the applicationmanagement of exchange of goods, services, events, experiences, people, places, properties, organizations, information and ideas. Where the marketer always seeks a response from your customer, stimulating the demand for their products (Kotler and Keller, 2012). Thus, Kotler and Keller (2012) divide marketing under a holistic looking into four main components originally used by McCarthy (1976) as a compound marketing (model the 4P):

- Product: the product or service are said to certain when they meet and or exceed consumer expectations, thus meeting some of the basic requirements of the product: size, quality and design.

- Price: the target consumer must feel that you are paying a fair price for the product, the price corresponding to the needs and the consumer desire to own the product or service.

-Square: It should be located next to the desired and advantageous market at the time of distribution, transport, storage and packaging. 
- Promotion:It is a set of actions that begins in advertising spends for public relations, sales promotion, personal selling and merchandising, which used the right way are able to stimulate the realization of sales. (COBRA, 2007)

These "4P's" serve as support for the marketing mix, seeking harmony and balance between the elements that compose it, which second Peci and Sobral (2013, p. 476) comment compose "[...] the set of variables on which the marketing manager will take decisions. " The "P" promotion, leading to this research encompasses all communication tools between organization and its public, something that gets specific space and expanded this research.

2.2 Communication, marketing and advertising

The specific subject of this research, advertising, it should first clarify what comes to communication, which, according to Sant'Anna (2002) is a process of three main structures: sender, message and receiver. Designed in the marketing context, to persuade, or to seek an effect calculated in attitudes and target audience behavior in function and a specific product, either by personal selling, promotion, merchandising, public relations, packaging, direct marketing, advertising or advertising. The last two, although commonly used interchangeably, they differ in concept. Advertising public drift (publicus Latin), which means the quality of what is public, making public a fact or idea. Propaganda (Latin (propagare) indicates the spread of principles, theories, relating specifically to the sale, the rhetoric at the idea. In this research, we opt for the use of advertising term, focusing on structuring disclosure in the case, specific research agencies.(SANT'ANNA, 2002)

According to the standard rules of advertising activity presented by CENP (1998), the body that regulates these activities in Brazil, we have that much advertising as advertising, pursuant to art. 2 of Decree No. 57,690 / 66, is taken as any paid form of dissemination of ideas, goods, products or services by an identified advertiser. Gomes (2003) outlines advertising as a form of communication that uses a set of paid media, and that affects the public and persuades to purchase goods or services andSant'Anna (2002) It defines the term as a mass communication technique, and pay with the purpose of providing information, develop attitudes and actions cause beneficial to advertisers.
The advertising business is established on the triad: the advertiser, the agency and the communication vehicle in which the owner starts the process by asking the service to the agency, which designs and supervises the placement of the vehicle (Cappo, 2003). This ratio must follow the rules presented by CENP (1998), in which:

Relations between Agencies, Advertisers and Media are at the same time, professional, commercial and have presupposed the need to reach technical excellence through professional qualification and the reduction of transaction costs among themselves, observing the principles of this instrument, ethics and good market practices by encouraging full competition in each of these segments. (CENP, 1998, p.6)

It is to emphasize the cultural and technological changes have transformed various aspects of society, encouraging new challenges to advertising inserted contemporaneously with Lévy (2010, p. 17) contextualized as cyberculture a "[...] set of techniques (material and intellectual), practices, attitudes, modes of thought and values that develop in a cyberspace "that is located in the world and global interconnection of computers (Lévy, 2010). These changes that also set in Lipovetsky (2007)calls hyperconsumption society, characterized by a greater democratization of comfort and leisure, attached to a trivialization of access to new and growing diversification of offers and products. In this new phase, new media are consolidated, decentralized and diversified, which take advantage of new technologies to provide new choices and individualized consumption. (Castells, 2002)

According Lapolli and Gauthier (2008), the main argument for the areas of sales were the numbers of the audience, especially in the case of TV. However, public engagement in online platforms and social networks becomes increasingly interesting. This situation intensified from the web 2.0, as the twenty-first century, they began to massively be available systems, applications and tools that offer the possibility of joint actions to users. These aspects result in the emergence of an individual with greater autonomy, situated on a context of rapidly changing technology and communication. This phenomenon was called "Culture Convergence" and is explained by Jenkins ideas (2008), which comes in two different models media, corporate or alternative, in which power production and distribution of content becomes technically accessible all.

then questions the convergence towards the public's attention through the many 
communication options, as well as delete the remuneration obtained through traditional communication vehicles. Thus, it emphasizes creativity as a crucial point, no longer seen as just the creative department function, but all previously bureaucratic sectors such as the media, for example. (Cappo, 2003)

2.3 Communication and Internet
Vehicles

In contemporary times, where is the media worldwide proliferation (O'Guinn, ALLEN and Semenik, 2008), companies use is a high variety of communication vehicles to get their message to the target audience, thus compounding the media, as radio, newspaper, magazine, television and the internet, for example. However, it is observed that there is no ideal media, depending on the choice of that the objective of the advertiser, the creative needs, the competitive challenge and the availability of financial resources in addition to considering the nature of the product or service being advertised attached to communication vehicle characteristics. (Shimp, 2009)

For a long time, radio was the primary means of mass communication, offering programs for all public profiles, but with the growth of television, from the 50, it creates a new communication universe, which caused the restructuring of existing resources, structured on television. Similarly occurs contemporary change to internet television, embodied advertising maneia in electronic banners (O'Guinn, ALLEN and Semenik, 2008). This technological evolution provides the gain of other features, making them more attractive and enabling a more efficient interaction with the user, stratified according to Gabriel (2010), according to the strategies used by companies: online presence; e-mail marketing; social networks; and search marketing.

Thus, the target audience of the marketing campaign is not only designed as a 'target', but as a media generator and transmitter of it. Gabriel (2010, p.109), "[...] we can not assume that our audience behaves like a" target "waiting to be" hit "- that is more appropriate for consumers highly controlled traditional media." Therefore, some advantages presented by the use of the Internet as advertising media are highlighted:

- Driveability - direct messages to specific targets;
- Tracking - track how users interact with brands;

- Flexibility - you can monitor and adjust the campaign at any time;

- Accessibility - available to users 24 hours a day; and

- Interactivity - the user can talk to the company to make the purchase. (PINE, 2008)

\subsection{Publicity agencies}

Regarding the regulation, which defines the advertising agencies, according to Law No. 4,680, of June 18, 1965, duly regulated by Decree No. 57,690, of February 1, 1966 has that in its Art. 6 to advertising agency is:

[...] Specialized in corporate methods in art and advertising technique, which through professionals at your service, studies, designs, executes and distributes advertising to Disclosure Vehicles, order and account advertiser clients with the purpose of promoting the sale of goods, products and services, disseminate ideas or inform the public about organizations or institutions they serve. (BRAZIL, 1966)

As for its operation, Shimp (2009) comments that advertisers have three alternatives to perform the same advertising function: hold internally; buy single services, as needed, specialized companies; or select a full advertising agency for its accomplishment, as regards the latter, advertising agencies, four are its main functions: creative services; media services; research services; and account management. Thus, it is observed that an advertising agency has the main function planning advertising communication of its customers and the creation and subsequent production of advertising production, study and determination of the best alternatives in the selection of media vehicles, referral for placement production and final assessment of the results to the client who hires the service (PINE, 2008). To Shimp (2009) four are the functions of an advertising agency: creative services; media services; research services; and account management.

With the dramatic changes that have taken place in the sector in recent years, Cappo (2003) states that traditional advertising agencies lost space. When most of the marketing costs were for television, the agencies have a clear role: doing research on mass audiences, create compelling and put these commercials commercials on TV. Everything else was just an addition to basic television campaign. This simple solution for advertisement does not exist because the TV does 
not dominate the whole way scenario, as before, so the use of neutral media strategies is necessary to advance in all positions to grope the market and win customers.

2.5 The relation between vehicle and agency

The body that regulates the advertising market in Brazil is the CENP (Executive Board of Standard Norms), an entity created and maintained by the private sector to ensure good practice among advertisers, advertising agencies and media, whose "Standards-standard Advertising activity "1998 currently apply. Operates to ensure the technical quality of advertising agencies, ensuring their physical and personnel structure, accrediting the various services, maintaining a deposit of the price lists of the various instruments and media at the same time acts as a permanent forum for technical discussion the advertising-commercial area. (CENP, 2016)

The agency, according to the CENP (1998) should use the absolute impartiality in the selection of suitable vehicles for advertising communication of its customers; on the other hand, it is for vehicles comply with the agency as intermediary legitimizes the process, whose performance will result in benefits for the advertiser as to the vehicle. (PINE, 2008)

\subsection{Strategy}

A term widely used strategy as defined by Mintzberg and Quinn (2001), it is consistent path determinations for the organization to act on the external environment obtaining competitive advantages for the same (Barney, Hesterly, 2007). However, it is noted that this concept has several approaches, a multitude of settings for each situation in which it is referenced. As an example, there is the definition of Chandler (1962), where the strategy is the determination of long-term organizational goals, as well as the allocation of resources needed to achieve this goal. Ansoff (1990) expands the definition of Chandler (1962) to include in its strategic planning model two key concepts: analysis of deviations, ie a check between planned and carried out; and synergy, as regards use of combined powers of two or more departments or organizations.
Other work to be noted is the Mintzberg (1987), which presents five "P's" strategy: plan (plan); pattern (default); position (position); ploy (maneuver); and perspective (perspective). Similarly, we have also the classic definition of Snow and Hambrick (1980), where the strategy is a pattern of making important decisions for the maintenance and organizational alignment with the context in which it operates, as well as management needs internal organization.

From the foregoing, it can be said that advertising agencies need strategies to address customers the best possible information of the vehicle, in line with market rules granted by external mediators and adapting to the rapidly changing industry.

\section{Methodological procedures}

This research is classified as exploratory and descriptive. Exploitative by providing greater familiarity to the topic, analyzing it and making it more explicit, for this step,It was used bibliographical and documentary research. And also descriptive when you want to describe specific characteristics of a given population, this step took place multicases study Florianópolis advertising agencies, seeking an in-depth details of the study object. (GIL, 2010)

According to the nature of the data collected, the research is characterized as qualitative, such that consider communication researcher in the field with the explicit part of knowledge production, showing variety of perspectives on the subject, from social meanings and subjective related to it . (FLICK, 2009)

The research universe consists of the advertising agencies in Florianópolis / SC registered in CENP (National Council for Standard Norms), which regulates advertising activity in Brazil. The list was generated through the website of CENP (2015), held on 7 March 2015 and follows represented by Table 1, totaling 30 branches of possible observation. One has to point out that this universe was excluded Koerich Advertising agency because it is a "house", meaning that there is to meet an exclusive company.

Frame 1 - Florianopolis agencies certified by the CENP

\begin{tabular}{|l|l|}
\hline On one. & Fantasy name \\
\hline 1 & Neovox \\
\hline 2 & squeeze Communication \\
\hline
\end{tabular}




\begin{tabular}{|c|c|}
\hline 3 & agency Mob \\
\hline 4 & model Propaganda \\
\hline 5 & BZZ MultiComunicação \\
\hline 6 & Strategy Marketing Mix \\
\hline 7 & $9 \mathrm{MM}$ \\
\hline 8 & Advertising market \\
\hline 9 & D / Araujo \\
\hline 10 & Quadra Communication \\
\hline 11 & Onewg MultiComunicação \\
\hline 12 & Creation agency \\
\hline 13 & Communication intelligence \\
\hline 14 & interactive communication \\
\hline 15 & propagate \\
\hline 16 & Formula Communication \\
\hline 17 & Novita Communications And Marketing \\
\hline 18 & DBS Multi \\
\hline 19 & Sambba \\
\hline 20 & Gr Communication \\
\hline 21 & Toro Communication \\
\hline 22 & Air Advertising And Propaganda \\
\hline 23 & Marcca Communication \\
\hline 24 & Qing Communication \\
\hline 25 & Ezcuze Advertising \\
\hline 26 & Gas multi-agency \\
\hline 27 & Tutano Communication \\
\hline 28 & decision Communication \\
\hline 29 & Koerich Advertising \\
\hline 30 & Sonata and Advertising \\
\hline
\end{tabular}

Source: Adapted from CENP (2015)

The agencies were then contacted via email or phone, allowing the scheduling of interviews with eleven (11) representatives, these two had post of president, seven direction and two management. The sample was therefore not probabilistic and mainly defined by access, in order to interview owners, partners, presidents, directors or managers of agencies, focusing on the areas of care, planning and media.

Thus, this study is divided into two steps. The first comprises the secondary data obtained through bibliographical and documentary analysis in books, journals, newspapers, magazines, websites, research and industry information related to the national advertising market, state and local levels, formulating the basis for structuring the problem situation, theoretical basis, objectives and the creation of the collection instrument.
In the second phase, interviews were conducted in depth with leaders of Florianópolis advertising agencies contacted, using a semistructured script It builds on the theoretical foundation. For the structuring of choosing a vehicle of communication factors used in Question 2, they were used as the basis dimensions presented by Fahey and Randall (1999) that support the competitive position of a company.In other issues, he sought to observe the proximity of advertising, regarding the changes in the media with the agency strategy actions, taking the bases, or "P's" of Mintzberg (1987), later translated into four points addressed by the authors of the advertising and marketing industry: relationship, training, regulation and result (Castells, 2002; Cappo, 2003; Santaella, 2003; Jenkins, 2008; PINHO, 2008; shimp, 2009). For the script validation was performed a pretest to the director of an agency in Joinville on March 2, 2015.

Data collection took place from March 13 to May 13, 2015. Interviews were conducted individually,in room reserved in their own agencies, and are recorded for later transcription. Respondents were able to discuss their ideas spontaneously, leaving the researcher just listen and conduct the interview as structured script. Importantly, the data represent the perceptions of respondents at that particular time.

The recordings of the interviews were transcribed and the data were analyzed qualitatively taking into account the views and comments of respondents. Data analysis summarized in a process of verification and interpretation of the information collected, followed by reduction, preparation and presentation. In analyzing the issue that contained planning factors, the factors that had the minimum coincidence of at least five equal responses, representing almost half of the respondents were highlighted.

As the research limitation for only address the region of Florianópolis / SC because of convenience features and availability of researchers, it has been the inability to generalize the results at the state or national level. However, it should be noted that there is no impediment to the use of data or research results as a basis for future research, carried out in a similar way to other markets. 


\section{Presentation and Analysis of Results}

In Question 1, respondents indicated the estimated percentage media on the Internet authorized by your agency in the year 2014. With the exception of the Agency 6, the others are between 5 to $15 \%$, showing the little representation of this medium in advertising campaigns through agencies consulted. However, there is the Agency's information 3 that has a percentage of around $50 \%$, demonstrating a point outside of the curve. In such a confirming is operated, there is a case of the effectively perceived reality the target market. However, the percentage authorized media on the internet by the agencies consulted therefore presents a fashion of $10 \%$.

4.1 Factors for choosing a communication channel

In Question 2 was prompted respondents to draw up a ranking of 1 to 10,1 being the most important, of influencing more factors when choosing a communication vehicle for media campaign and to justify the choices of the first and last factors. Most respondents made the proviso that the weights of these factors vary widely according to the customer or the purpose of the campaign, but was oriented to respond according to what occurs more frequently in your agency.

Most of the factors did not show a pattern of responses. Considering an acceptable standard those factors that had at least five responses equal among respondents, the factors "Audience" and "Content" were elected the most important in choosing a communication vehicle, and on the other hand, "Opec"(Business Operations) and "Bonus" were the least relevant.

The choice of "Audience" as the most important factor in choosing a vehicle of communication explains the TV share of the lead in advertising revenue cake presented by InterMedia Project (2015), considering that it is the medium most used by the population Brazil, according to Brazilian media research (2015). Respondents who justified the choice of this factor showed that the leadership in audience indicates the vehicle can send the message to more people, but that should not be considered alone. Some respondents suggested that when assessing the audience, it is also necessary to evaluate the "price" (and thus obtain the CPM, or cost per thousand), the "Image and Reputation" of the vehicle and even the "Content", a factor that He ranked second in the ranking. That is, the "price" factors, "Image and Reputation" and "Content" can influence the choice of other vehicles even if they are not leaders in audience.

On the "Content", many respondents justified as the second most important factor because it is very tied to "rating" because it is the right content that attracts the audience with the profile you want. The interviewee of the agency 10 states that "the main criterion is the suitability of vehicle strategy, so Audience / Content are first." So once defined choice of vehicle depending on the audience, you have to match the media proposal convergent mode with the content.

On the other hand, at the other end of the evaluated factors, "Opec" was identified as a factor that little influence on the decision to be more linked to internal procedures and as shown by the respondent of the Agency 1, "in general, there are no large issues regarding this market. " On the "Bonus", some respondents recognize its importance for the agency, but all claim that it should not influence the choice of the vehicle process. According to the interviewee of the agency 10, "BV is last because it has to be the consequence of making a statement, not the cause."

Being "Opec" and "Bonus" less relevant factors among the alternatives described, it can not also be identified as serious impediments to the growth of the internet representation in the media by the total authorized agencies. This is because some of these vehicles have no Opec and do not offer bonuses, and sometimes even the discount standard agency.

Question 3 also uses the factors set forth in Question 2, but requested that the respondents do a comparative analysis of the factors that stand out in traditional media (such as $\mathrm{TV}$, radio, newspaper) and those who stand out in vehicles on the Internet. The most frequently cited factors in relation to traditional vehicles were "Image and Reputation," "Sales and Relationship" and "Audience". The interviewee of the agency 7 made a statement which helps explain this scenario:

Traditional vehicles have more organization, more relationships, size, and this gives a security. Because the internet have very new things, have the insecurity of income customer.(AGENCY 7)

Compared to traditional vehicles when considered the main factor derived from research 
to "Image and Reputation," followed by "Sales and Relationship", evidence of the strategy the standard and defined position by Mintzberg (1987). Whereas traditional vehicles make up the largest slice of the pie of advertising revenue, according to Inter-media (2015), it is clear that the factors of "Image and Reputation" and "Sales and Relationship" are more relevant to the choice of a vehicle than indicated by the responses Question 2. These factors could therefore gain more weight in the ranking.

Already the most cited factors for vehicles on the Internet were: "Content" and "flexibility". The first factor is cited because of the diversity of channels that the internet has, making it possible to offer different content and targeting of campaigns. This really is one of the great advantages of the Internet. But even that respondents consider the "Content" as the second most important factor in choosing a vehicle of communication, it seems that this spread of internet has not proved sufficient to boost their revenues on advertising.

On the "flexibility" he was cited ease of creating different shapes and the smooth exchange materials at any time, characteristics which are more restricted in traditional media. With the ease of measurement that the internet provides, it is much easier to evaluate a campaign and make the necessary adjustments at any time. However, although it seems an advantage for this flexibility agency also means increased efforts to create and media. It takes even more exercise creativity, increase knowledge and measure results. Therefore, this factor is also not enough to leverage the media investment on the Internet.

It notes that only when referring to vehicles on the internet is the "price" factor was cited. Whereas this is a very relative factor, as it must be analyzed as the audience, you can say the interviewees consider the vehicles on the Internet with relatively better price than traditional vehicles. But just as "Content" and "flexibility", the "price" was also not enough to increase the representativeness of the internet in the composition of the media agencies consulted.

When considering the advantage presented by the mainstream media in the cake composition of advertising investments compared to the internet, it can be concluded that the characteristics presented as highlighting the traditional, such as "Image and Reputation" are preponderant the highlighted features on the
Internet as the "Content". This runs counter to the results presented in the ranking of factors, the most relevant factors should be elected "Audience" and "Content". In the context of the marketing mix, presented by Cobra (2007), the Internet as advertising media needs to develop its "promotion", in order to match the image and reputation presented by the mainstream media, as the respondents have pointed out positive features about " price "and" product ".

\subsection{The relationship with the media}

Addressing the relationship between media and agencies, Question 4 asked the respondents pointed that strategic actions are carried out by their agencies to maximize the relationship with the media gains. The most frequent response was related to the provocation meetings with the vehicles, in order to carry out creations together and build custom formats. It is observed from the answers that most agencies are open and willing to approach and generate business. Respondents said that this approach is essential to know more about the vehicle, understand the possibilities and discuss new ideas.

Question 5 also addresses the relationship between vehicle and agency, but questions whether there are differences in this relationship when comparing traditional vehicles and vehicles on the Internet. All respondents stated that there are differences in this respect, except the Agency 11. The main difference is the more pointed relationship "cold" when it comes to vehicles on the Internet. On this issue, the interviewee of the agency 8 explains:

There are some differences. Traditional vehicles are expensive and it helps in that regard. But if you will buy Google / Facebook, does not have the same service. Or invoice. This impersonality is bad. In traditional vehicles, there is a partnership, joint construction.(AGENCY 11)

Still on Question 5, the interviewee of the agency 5 makes a statement that also addresses the most distant relationship of the vehicles on the Internet, deepening the sense of lack of direction for building a more effective campaign.

In the case of the Internet, not so much (the relationship with the agency). It is a means underutilized in terms of creation. Speaking in terms of media, I am clear that I must put, I know it works. But I think it lacks a little on the vehicle, which has all the technological expertise, tools, knowledge of what can be done, move on to the part of the creation of the agencies. It is no use just make a banner that is a "partizinha" newspaper ad.(AGENCY 5) 
Two other responses that draw attention, despite not being the most cited, is on legislation and the commission (the discount standard agency). The relationship between advertiser, agency and vehicles follows a clear regulation and widespread in the market, which is not always followed by vehicles on the Internet. interviewee of the agency 10 talks about this point:

It's very different, because the vehicles on the Internet, most of them do not fit or the law governing the relationship between vehicle and agency and advertiser. They are more informal relationships are relationships that have not yet defined rules, then no doubt is a relationship that one hand is more flexible, free, but on the other it is less clear.(AGENCY 10)

Even if the less attention has been appointed to the factors "Bonus" and "Opec" by respondents in Question 2, emphasis is placed on this topic a lack of clarity for trade relations with the vehicles on the Internet.

\subsection{The challenges faced}

In Question 6, all respondents stated that there were changes in advertising with the arrival of the internet. The main changes mentioned were the increased possibility of targeting, increased media options / vehicles and consumer interaction. Below is described a review of the Agency interviewed 8 on this issue:

Another point is about the thousands of options that exist today to invest your campaign. On the one hand it is legal, on the other hand is complicated because the line cake is almost the same. The first problem is that you think you have to be in all of them. Second is that the customer think you have to be in all of them, but can not afford to be in all of them, or do not have enough money to have a reasonable frequency in all of them, to bring results. This year the advertising pie will shrink, it becomes a great game of puzzle for the media professional how to ride with these millions of possibilities with the money he has. Now, there's more to say "take the money and puts all on TV"; for now the TV does not talk to the public and I have to start to understand how to use the internet to talk to this audience, if only to draw their attention to the TV somehow.(AGENCY 8)

Another interesting statement on this issue was the interviewee of the agency 10 , which addresses the improvement of consumer involvement:

The consumer is no longer passive and became active in brand communication and business. There is no longer a one-way street, it is now two-way. This greatly changed the way that businesses communicate with their consumers. No use I say my product is good, is the best, is the cheapest, and find that no one will answer that it is not true.(AGENCY 10)

When checking the reports of respondents in relation to changes in advertising with the advent of internet, it is clear that fall criticism of the model of traditional media like TV, which owns the preference of Brazilians. They present the various contributions and challenges that the Internet has brought to the field of communication.

Continuing this theme, Question 7 asked the respondents to report what the main challenges facing his agency with the growth of the internet as a communication medium. The most frequent response was the challenge of investing in employee training constantly. They cited the importance of having a technically qualified team that knows how to deal with so many new features that appear every day in this medium. Some agencies admit that when they lack the knowledge, resort to third parties, as pointed out by the Agency 8:

When I started working with advertising, I got a promotion and event agency in Sao Paulo. At the time, we were the "below the line" and almost 15 or $20 \%$ of the budget went to promotion. Over the years, the division has become $50 \%$. At this time, the large advertising agencies have started buying the promotion agencies. And today this movement happens. Arises a legal digital agency, begins to grow, it is a large group and purchase not to lose money. At the agency, we do little because, managerially speaking, little is invested in what has little volume. So, we prefer to work with partners, which has been our practice, than to develop internally.(AGENCY 8)

Another challenge was also mentioned in relation to the lack of knowledge, but this time the customer. The interviewee of the agency said that 1 on this subject:

We feel a very great difficulty in getting our customers understand what we are proposing. We have had a series of campaigns that present we focus a lot on the Internet, with relatively complex strategies, with a number of things that we realized it was beyond the capacity of understanding the customer. We are having to simplify, or do things without the customer know.(AGENCY 1)

It is common understanding that the distance of the agencies with the internet is due to a relative lack of this type of media and its potential, but is perceived lack of interest of some agencies to "embrace this cause." Limited to the internal training and using third-party palliative way, there is evidence of a reactive posture of some agencies the profound changes that the Internet has brought to advertising, cited in the previous question, letting them stay in their traditional style.

Another challenge addressed and that contributes to this accommodation state, it is the difficulty to monetize more with the internet. Again, it was mentioned the lack of definition of 
agency commission for all vehicles on the Internet, according to comments the Agency 3: "Our regulators have not established a form of commission on all internet vehicles." In this regard, the Agency 2 points to the issue of low profitability:

Today as I have many other options, the amount of stuff I have to create is very large, with lower costs. So the challenge for us as an agency, it's like I monetize this, because it has no pattern. Before I had half a page, a page, 30 seconds. And with these other various formats and possibilities, I can not pass it to the client. And the ease of exchange of content on the Internet, the client wants me to change even more.(AGENCY 2)

Therefore, the difficulty of constant training, lack of knowledge of advertiser clients and the low profitability of internet configure the challenges that the agencies consulted more have faced with the growth of the internet as a communication medium. As mentioned, these challenges have proved major barriers to update the advertising business model, leaving the agencies attached to the traditional model.

Question 8 asked respondents to indicate what challenges the media outlets on the Internet have to face to gain more importance in customers' campaigns your agency. The most frequent response was related to better reflect the return of possibilities for customers. This issue also goes through what was mentioned in the previous question, about the lack of market knowledge on this type of media. So, to show the possibility of return to customers, they will feel more secure in hiring this type of media.

It was also questioned by the interviewees the actual return that the internet offers as advertising media. Some said that it's not a similar result to which the traditional media often provide. The interviewee of the agency 8 further complements and reinforces the importance of showing the "return":

Two things are basic: the first is you can prove that people really pay attention to advertising on the Internet. They provide, as we have several cases of companies that grew based on this type of advertising. The advertiser has doubt on the effectiveness of the banner. I sell 1 billion views, but is watched? Do they not bother? The second is conversion. The customer wants to see the sale. But do these actions generate results? Sell more? This is the great difficulty. I think the biggest mistake of a vehicle is trying to prove that is a leader in something. He has to prove that gives return.(AGENCY 8)

However, it is questionable this kind of statement when confronted with the question of previous answers, pointing to the lack of expertise of some of the agencies consulted in this type of media. The internet requires different expertise, analytical view of data and different formats that are worked in traditional media, as they must be less interruptive. Perhaps the questions regarding the outcome of the Internet have been made based on the lack of ability to build a campaign that meets these specifications.

Then it was appointed on the remuneration of the agencies with these vehicles. The interviewee of the agency said that 7

The question of agency remuneration is still a matter to be discussed as well. There are many issues in setting. Lack a way to make the agencies realize how much they can earn, lack thinking about how agencies can be better paid.(AGENCY 7)

However, these claims are contrary to what was indicated on the low influence of the "Bonus" in choosing a vehicle of communication. Although it was cited by only two agencies in question 8 , it is necessary that this factor is observed more relevant to Internet growth in advertising investments.

\subsection{The advertising market of Florianópolis}

Finally, Question 9 is broader questioning about the timing of the advertising market of Florianópolis. All said that the market is going through a difficult time, some have more pessimistic, as the respondent of the Agency 2:

It is a gigantic crisis. We're in a business model exhausted and the crisis of the economy I think it's much worse ... I have talked to other owners of agencies and they are terrified, laying off many people, I'm thinking where will it arrive, if it's time to separate those who will survive and who will not. Many will leave the market.(AGENCY 2)

The interviewee of the agency 10 also passes a more optimistic message, believing in evolution of Santa Catarina market as a whole, despite the economic crisis in the country. She says:

Despite the difficult economic times, the willingness of advertisers, the Santa Catarina market has grown a lot. And will continue to grow, not only in mathematical terms, but in terms of maturing, with conditions provide better service, better advise their customers with more strategic concern, more foundations, more focus on results. (AGENCY 10)

On the other hand, the interviewee Agency 8 has a description even broader market the time of this state, showing concern with excess "regionalismo".

Our market is very regional, different from Curitiba and Porto Alegre who can get national customer accounts. So, we started to have some problems, how to work with very little information, very with "guesses", all with 
common information. How do you define a strategy without relevant information? If you do not have these data, no planning. Thus, we can not have a relevance to the client's business. The agencies are beginning to get very similar to each other. If I'm not relevant, the negotiation of compensation with the customer becomes more difficult, enter the monthly fee model, which is interesting for the cash flow, but is not consistent with my production. Thus, the agency lives tight, with little time, with volume giant work, and there the quality is pushed down. This becomes a vicious circle. We have in $\mathrm{SC}$ is much to question the "owner of the agency." This ends up pulling for non professional. If not in the professionalization and not seek this relevance, we will continue limited to our regionalism.(AGENCY 8)

Ratifying the characterization of Florianópolis market placed by the respondent as "regional", there is, from the considerations and views expressed, the existence of a certain empiricism and cronyism in relations between clients and agencies, giving rise to a lack of relevance agency's role in the business customer.

\subsection{Consolidation of strategic actions}

As a result of the research, the main points discussed were organized according to the following perspectives: relationships, training, regulation and result.

The relationship perspective stands in the disadvantage that the internet medium is related to the factors "Image and Reputation" and "Sales and Relationship" compared with traditional means. Despite the many advantages of using the Internet as advertising media, as shown by Pine (2008), little development factors linked ahead of sales and marketing are weighing negatively on the side of the vehicles on the Internet. As a result, the agencies interviewed point out the relationship "cold" vehicles on the Internet, making the joint construction of solutions and the promotion of business. In addition, one of the main advantages cited for the internet is the "flexibility", indicated by the agencies as essential in the relationship with the vehicles. However, the lack of a close relationship of the vehicles on the Internet appears as a barrier to further exploit this feature. Thus, the relationship with the agencies needs to be developed by the vehicles on the Internet, leaving aside the impersonality currently the distance agencies and advertisers.

The training perspective stands out when respondents recognize the potential of the Internet, but take the lack of market knowledge on how to use it in the most appropriate way in an advertising campaign. Castells (2002) and
Santaella (2003) state that new technologies have enabled consumers to take a more active stance regarding communication with brands and agencies need to adjust their strategies to adapt to these changes. Therefore, the main challenge pointed out by the agencies is to maintain their often trained teams to work with the internet, and face the lack of training of its customers. At the same time, the agencies expect from the Internet communication vehicles is just better reflect the return that offer as advertising media to facilitate this understanding of the market. The training agencies and clients is vital if they are able to build and understand effective strategies and to break their insecurities when it comes to the digital universe.

Another challenge is whether regulatory adherence of vehicles on the Internet. This is essential to address the barriers that still show undefined in its relationship with agencies and advertisers, as the remuneration of the agency, pricing and billing forms. clear rules in this regard would facilitate the creation of a more costeffective and transparent business model for everyone involved. The fact is that this issue is very well designed for traditional vehicles, especially in the remuneration issue. In this sense, Pine (2008) Cappo (2003) point out that this situation results in a dependency on agencies over traditional vehicles.

In addition, to follow this regulation, the partnership between vehicles on the internet and agency would be made official by avoiding the direct purchase by the advertiser, which makes this means of communication outside the general strategy developed by his agency. With this, more businesses could be promoted through the agency, including allowing $\mathrm{BV}$ institution to compete more equally with the model used by traditional media. As pointed out by the survey, despite the "Bonus" to be one of the least important factors for choosing a vehicle of communication in many other answers and comments, this query was considered important by respondents to the vehicles on the internet to gain more representation in media investments.

Regarding the result, only saying that has audience is no longer enough. Despite being the most important factor that influences the choice of a vehicle, the internet has been questioned about its effective results as advertising media, as has been pointed out by Cappo (2003) and Shimp (2009). So one of the main challenges identified 
by the agencies for the development of vehicles on the internet is better translate the results they can offer customers. However, we need to translate these results through the plethora of data that the Internet has, indicating the return that can be measured far beyond just "clicks".

For this it is necessary to go beyond the banner advertising format commonly used on the Internet that is measured by impressions and clicks. We must understand that it has created a new culture from the new media, as pointed out by Jenkins (2008) on the convergence culture, where corporate media and alternative act simultaneously. Another important feature goes against the main feature of traditional advertising, the interruption. On the internet, this advertising format is hardly accepted by users: advertising content must be "disguised" editorial content.

Thus, the outlook observed in the field of research (relationship, training, regulation and result), when collated with the theoretical framework on marketing, advertising and strategy, give off are the following possible strategic actions to internet communication vehicles:

a) Promote professional relationships with advertising agencies and advertisers in order to improve their commercial services and perform the joint construction of the campaigns on the Internet;

b) Present digital media as an alternative to advertising agencies based on the relationship with traditional media, especially in terms of agency remuneration and volume incentive plans;

c) Create vehicle networks on the Internet, for example networks of blogs, in order to gain relevance and to unify its business operations;

d) Create doubts care for channels and promote training to advertisers and agencies par reduce uncertainty to invest in new media;

e) Work together to advertising students to be formed more skilled professionals to work with digital media;

f) Acting through professional bodies in regulating the digital advertising market so that the business models and actors involved not fall within the law and can act with clearer rules;

g) Offer advertising formats that have more return on the Internet as an alternative to banner, which has been widely criticized for advertisers and users - offer formats that are less disruptive and are mixed with the content they get the attention of consumers;

h) Reposition the digital media within the advertising to be considered as favorable for advertisers and agencies as to traditional media.

\section{Conclusions}

Considering the overall objective proposed for this research, regarding characterization of the perceptions of advertising agencies in Florianópolis on the development of communication media on the Internet, if feasible from the strategic actions previously proposed based on four perspectives derived search: relationship, training, regulation and result. This context was derived from the understanding of the perceptions of the agencies in their relationship with the vehicles on the Internet and analysis based on the specific theoretical framework.

In summary, the research shows that vehicles on the internet need to have a close relationship, maintain qualified market have a regulated relationship with key influencers in this market, advertising agencies, and show results. The internet gains more importance in people's lives and therefore gain more representation in advertising, to the extent that will be required such adjustments in trade relations, the advertising practices in professional and business models.

On the factors that influence the Florianópolis advertising agencies in the choice of vehicles used in a communication plan, it was found that the order of importance of these factors is quite relative, but when it comes to the most and least influential factors was possible to establish a standard answers. The most influential elected were "Audience" and "content", and the less influential "Opec" and "Bonus". It is important to highlight the various reservations about these factors presented in this work. Factors "Image and Reputation" and "Sales and Relationship" highlighted prominently in traditional vehicles could have been presented with more relevance in the rankings, as they are features that differentiate the means with greater representation in advertising revenue. Likewise, one must also question the factor of the "Content", because even being touted as the most relevant second to choosing a vehicle and appointed as a differential to the internet, this could not raise the productivity of this type of media the agencies. Finally, despite the "bonus" was less relevant 
elected, he appears as an important point in the relationship between vehicle and agency in various other responses and comments of respondents, and therefore should not be overlooked.

To characterize the strategic actions of Florianópolis advertising agencies in their relationship with the media, most of the respondents said they are active in this process, choosing to lead meetings with vehicles for joint construction of solutions to customers. However, when making the comparison between traditional media and the Internet, respondents said that vehicles on the internet are more "cold" and they often do not follow the rules governing the relationship between agency and vehicle, unlike traditional vehicles that have this issue very well settled. Thus it was found that the aforementioned meetings are held most commonly with traditional vehicles, which makes this distance with the vehicles on the Internet impede the construction and implementation business.

The main challenges faced by Florianópolis advertising agencies with the growth of the Internet as a means of communication are: the difficulty of constant training of its staff, the lack of knowledge of advertiser clients and the low profitability of the Internet. The constant changes in technology and the numerous possibilities offered by the Internet hamper the learning market, which feels insecure in using this type of media. On profitability, he cited is the lack of definition of the remuneration of the agency and the increased workload due to the ease of exchanging material and increase options to be worked.

However, it was concluded that one of the main barriers to the development of the Internet as advertising media is also in the lack of interest or willingness of agencies to make it happen. Although they stated that there were changes in advertising with the advent of the Internet, the agencies have become rooted in the traditional model of advertising, more profitable, and mostly limited to the internal training for its development in the market.

Finally, at the intersection of literature on the subject and the discourse of respondents, this work offers the advertising market a number of contributions regarding the challenges faced with the rise of new technologies. Regarding the contribution to the media on the Internet, it is recommended to split the four perspectives described above (relationship, training, regulation and result) in order to break down the barriers that hold its development as advertising media. Highlights the need for more effective action regarding these points mainly by entities representing this class, directing discussions on these guidelines and contributing to increase the competitiveness of the medium in advertising.

This study also provides contributions to advertising agencies that, through discourse of the interviewees present themselves comfortable in the traditional model. However, from the rise of the internet representation in people's lives, the agencies will no longer be shown unwilling to develop in this direction. Increasingly, these new opportunities will arise, so agencies need to understand this moment and prepare to exploit more efficiently all the possibilities of communication with consumers. In this sense, it is the contribution also to advertisers, to be vigilant in choosing their agencies and the development of their communication objectives.

You can also observe contributions to traditional vehicles. Supported a regulatory model and very well established remuneration in the Brazilian market and is condemned by other markets in the world, it is the recommendation also to adapt to new technologies. Many vehicles already have their digital platform, but still is the challenge to become as relevant as the Internet are on your media source. In the same way that has been described in relation to advertising agencies, traditional media need to be prepared for the best broadband infrastructure in Brazil, the digital culture that new generations are being submitted and the strong growth of search platforms, social and Mobile.

For future studies, it is suggested as a possibility a theme with further research in other contexts and places, amplifying the perception analysis of the front advertising agencies online challenges, see that this research was limited only to the city of Florianópolis.

\section{References}

ADLER, RP; FIRESTONE CM The conquest of attention. São Paulo: Nobel 2002.

LOVE. Definition of Marketing. Available at:

<https://www.ama.org/AboutAMA/Pages/Definiti on-of-Marketing.aspx>. Accessed on: 10 October 2016. 
ANSOFF, H. Igor. The new business strategy. São Paulo: Atlas, 1990.

BARNEY, JB; Hesterly, WS Strategic management and advantage competitive. Sao Paulo: Pearson Prentice Hall, 2007.

BRAZIL. Secretariat of Social Communication of the Presidency. Brazilian search Media 2015: consumption habits by the Brazilian population. Brasilia: SECOM, 2015.

BRAZIL. Decree 57690 of February 1, 1966. Approves the Regulation for the implementation of Law No. 4,680, of June 18, 1965. Official Gazette of the Federative Republic of Brazil 1966.

BRIGGS, A ; BURKE, P. A media social history: Gutenberg to the Internet. 2nd Ed Rio de Janeiro:. Jorge Zahar Ed., 2004.

Cappo, J. The future of advertising. São Paulo: Editora Thought-Cultrix 2003.

Castells, M. The network society - the information age: economy, society and culture Volume 1. São Paulo: Peace \& Earth 2002.

CENP. Standards-standard advertising activity. São Paulo, 1998.

CENP. What is the CENP. Available in $<$ http://www.cenp.com.br/sobre-o-cenp/o-que-eocenp>. Accessed on: 28 June 2016.

CENP. Certified agencies. Available in: https://sistemas.cenp.com.br/WebCENPConsulta/ ConsultaWeb.aspx. Access 07 of March. 2015.

CHURCHILL, GA; PETER, JP Marketing: creating value for customers. São Paulo: Saraiva, 2000.

COBRA, Mark. Marketing Basics: A Brazilian perspective. São Paulo: Atlas, 2007.

comscore; IAB BRAZIL. online media investment numbers 2014-2015. São Paulo, 2015.

Fahey, Liam; RANDALL, Robert M. MBA: Practical Course: strategy. Rio de Janeiro: Campus, p. 100, 1999.

FLICK, U. Introduction to qualitative research. 3. ed. Porto Alegre. Artmed / Bookman, 2009.

GABRIEL, M. Marketing in the digital age: concepts, platforms and strategies. São Paulo: Ed Novatec, 2010..
GIL, AC How to develop research projects. 5. ed. São Paulo: Atlas, 2010.

GOMES, ND Advertising: Persuasive Communication. Porto Alegre: Sulina, 2003.

INSTITUTE MAPA. Marketplace ad serving Santa Catarina. Florianópolis, 2013.

JENKINS, H. Culture of convergence. Sao Paulo: Aleph, 2008.

Kotler, P; KELLER, KL Marketing management. 14th Ed São Paulo:. Pearson Prentice Hall, 2012.

LAPOLLI, M ; GAUTHIER, F. Advertising in the digital age: a challenge for today. Florianopolis Pandion, 2008.

Lipovetsky, G. paradoxical happiness: essay on hyperconsumption society. São Paulo: Companhia das Letras, 2007.

McCARTHY, J .. Basic Marketing: A managerial vision. Rio de Janeiro: Zahar, 1976.

Mintzberg, H. The strategy concept I: five Ps for strategy. California Management Review, Fall, Vol. 30, n.1, 1987.

Mintzberg, H .; QUINN, JB The strategy process. 3. ed. Porto Alegre: Bookman, 2001.

O'Guinn, TC; ALLEN, Chris T .; Semenik, Richard J. Advertising and integrated marketing promotion. 4. Ed, England:. Cengage Learning, 2008.

OKADA, SI; SOUZA, DE EMS. Digital Marketing Strategies in the Era search. Journal of Marketing, Vol. 10, no. 1, p. 46-72, 2011.

PINE, JB Communication Marketing: principles of marketing communication. 9th Ed Campinas. Papirus, 2008.

Lévy, Pierre. Cyberculture. 3. ed. São Paulo: Ed 34, 2010..

INTER-MEDIA PROJECT. advertising investment report. São Paulo, 2015.

SANT'ANNA, A. Propaganda: theory, technique and practice. São Paulo: Pioneering 2002.

Santaella, L .. Culture and Arts posthuman: the culture of the media cyberculture. São Paulo: Paulus 2003. 
Shimp, TA integrated marketing communication: advertising and promotion. 7th Ed Porto Alegre. Bookman, 2009.

SNOW, C .; Hambrick, D. Measuring organizational strategies: some theoretical and methodological problems. Academy of Management Review, v.5, n.4, p. 527-538, 1980. 